\title{
Philosophiques
}

\section{Bessone sur la race et la culture}

\section{Chike Jeffers}

Volume 40, numéro 2, automne 2013

URI : https://id.erudit.org/iderudit/1023708ar

DOI : https://doi.org/10.7202/1023708ar

Aller au sommaire du numéro

Éditeur(s)

Société de philosophie du Québec

ISSN

0316-2923 (imprimé)

1492-1391 (numérique)

Découvrir la revue

Citer ce document

Jeffers, C. (2013). Bessone sur la race et la culture. Philosophiques, 40(2),

473-477. https://doi.org/10.7202/1023708ar

Ce document est protégé par la loi sur le droit d'auteur. L'utilisation des services d'Érudit (y compris la reproduction) est assujettie à sa politique d'utilisation que vous pouvez consulter en ligne.

https://apropos.erudit.org/fr/usagers/politique-dutilisation/
Cet article est diffusé et préservé par Érudit.

Érudit est un consortium interuniversitaire sans but lucratif composé de l’Université de Montréal, l'Université Laval et l'Université du Québec à Montréal. Il a pour mission la promotion et la valorisation de la recherche. https://www.erudit.org/fr/ 


\title{
Bessone sur la race et la culture
}

\author{
CHIKE JEFFERS \\ Département de philosophie, Dalhousie University \\ Chike.Jeffers@Dal.Ca
}

La publication du livre de Magali Bessone, Sans distinction de race? constitue une étape importante dans le développement de la philosophie des races [philosophy of race] en tant que domaine de recherche spécialisé. Bessone n'est pas la première philosophe à écrire sur les races en français - après tout, le célèbre Voltaire appartient à ces penseurs des Lumières qui permit de faire émerger le discours sur la race que nous connaissons. Plus récemment, des philosophes français comme Étienne Balibar, Pierre-André Taguieff et Elsa Dorlin ont aussi écrit sur les races. Cependant, si je ne me trompe pas, le livre de Bessone est le premier livre en français à traiter en profondeur du large corpus - et en continuelle expansion - de la philosophie anglosaxonne [anglophone] sur la race. Ce point est important, car c'est seulement dans le monde anglo-saxon [anglophone], et pour l'essentiel aux États-Unis, que la philosophie des races est devenue un champ d'étude dynamique et reconnu par les philosophes professionnels contemporains. Bessone s'appuie habilement sur le travail qui a été fait en anglais et offre une perspective proprement française sur ce travail, ce qui conduit à une extension du domaine de la philosophie des races particulièrement utile et bienvenue. Tout comme Albert Atkin, un philosophe britannique établi en Australie, et qui a récemment publié un livre intitulé ThePhilosophy of Race (Acumen, 20I2), Bessone contribue à l'entreprise importante qui consiste à rendre la philosophie des races moins américaine, tout en apportant à son contexte nonaméricain les bénéfices du travail d'ampleur qui a été fait en Amérique.

Bien sûr, équilibrer ces deux réorientations est un défi intéressant. L'introduction du livre de Bessone montre d'ailleurs clairement son désir de parler à partir et à l'endroit du contexte français, mais les traits distinctifs de la France comme lieu de réflexion sur la race n'apparaissent peut-être pas de manière suffisamment claire avant le dernier chapitre qui porte sur les moyens d'atteindre la justice. La plupart du livre est si profondément engagée dans les débats et la plus récente littérature en anglais que l'on peut presque oublier qu'il est français, si ce n'est qu'il est en français. Et je ne dis pas cela pour dénigrer le livre: je crois au contraire que Bessone rend un grand service à la philosophie française et francophone en discutant aussi bien les différentes positions classiques que le travail de pointe qui se fait en anglais. Cela étant dit, la façon dont le livre est à la fois très français et, à d'autres moments, à travers les débats où il s'engage et la littérature qu'il mobilise, très américain, rend sa lecture d'autant plus fascinante, ici, dans le contexte canadien, et tout particulièrement le contexte francophone. 
Les commentaires critiques sur le livre que je voudrais maintenant exprimer peuvent être liés, me semble-t-il, à certains aspects du contexte canadien, même si je ne m'attarderai pas davantage sur cette relation. Comme Bessone, je défends le constructivisme social dans le débat en philosophie sur la métaphysique de la race. Selon cette position théorique, les races ne sont pas des sous-ensembles biologiques de l'espèce humaine comme on les a traditionnellement comprises, mais elles correspondent néanmoins à des clivages sociaux réels. Bien que Bessone et moi soyons d'accord pour dire que les races sont une réalité sociale, nous nous séparons sur le rôle que joue la différence culturelle dans la réalité sociale de la race. Bessone nous dit qu'une race est « un groupe fluctuant déterminé par des traits visibles fonctionnant comme des étiquettes faillibles associés à des traits déterminés sociologiquement et correspondant à une histoire continuée de domination et de conflits sociaux» (II4). Je pense que c'est vrai, mais je voudrais aussi souligner, contrairement à Bessone, que la détermination sociologique des groupes raciaux est en partie une question de différenciation culturelle. En effet, ce n'est pas simplement une question liée à l'existence de stéréotypes raciaux qui attribuent de façon illégitime un petit groupe de caractéristiques culturelles à tous les membres des différentes races, ce qui implique souvent que ces caractéristiques sont le fruit d'essences biologiques. Je veux plutôt parler de ces identités raciales qui sont le fruit sociologique de l'acceptation généralisée de distinctions raciales. De nombreuses personnes qui ont été socialisées de manière à se considérer comme membres de telle ou telle race voient le fait d'y appartenircomme un élément important d'elles-mêmes, et cela affecte la façon dont elles pensent et agissent, ce qu'elles apprécient, avec qui elles s'associent, comment elles développent des formes de communauté, et tous les autres aspects de leur vie culturelle.

La nature et la valeur de l'identification raciale n'occupent pas une place importante dans la théorie de la race de Bessone, si bien qu'elle arrive à des conclusions sur la nature et la valeur de la race qui sont, à mon sens, trop rapides. Elle associe le constructivisme social à l'idée que "[1]a race est moralement et politiquement condamnable» et donc que «[l]e monde serait meilleur si l'on pouvait se débarrasser de la race » (I I 5). Cela suggère qu'il y a, par exemple, quelque chose de moralement et de politiquement condamnable dans la catégorisation des personnes comme noires, et que le monde serait meilleur si nous nous débarrassions de cette catégorie. Une telle position apparaît fausse à de nombreuses personnes noires, moi y compris. Nous pouvons certainement dire que le fait qu'être noir a été construit comme une position désavantageuse et qu'un signe d'infériorité est quelque chose de mal, à la fois moralement et politiquement; nous pouvons aussi dire que le monde serait meilleur si de tels désavantages et dépréciation disparaissaient. Mais il est aussi possible de désirer la fin de toute corrélation entre le fait d'être noir et celui d'avoir un statut inférieur tout en voulant que les noirs 
continuent à s'identifier les uns aux autres, pour autant que l'on valorise les liens culturels noirs. Si ce désir est uniquement enraciné dans la fausse croyance que les personnes noires sont naturellement un peuple pour une raison de biologie, alors c'est un problème, et cette erreur doit être dénoncée. Mais il demeure possible de valoriser l'identité culturelle noire tout en acceptant que la race est une construction sociale, et tout en reconnaissant que la fonction d'origine de la catégorisation raciale était de placer les gens dans une hiérarchie sociale. Dans cette perspective, les efforts des personnes d'ascendance noire africaine pour investir une catégorie destinée à les dévaloriser peuvent être appréciés comme un épisode d'une histoire admirable de résistance.

Bessone demeure toutefois très sceptique quant à la cohérence et au bien-fondé d'une liaison étroite entre race et culture. Elle exprime en particulier ce scepticisme dans les chapitres IV et VI. Je voudrais concentrer mes derniers commentaires sur sa critique du multiculturalisme dans le sixième et dernier chapitre. Bessone prend une position que d'autres ont pris avant elle, et définit le multiculturalisme, dans une perspective antiraciste, comme une diversion: "L'attention portée à la différence fait oublier l'existence du racisme comme institution sociale fondée sur une hiérarchie de statuts formelle et comme ensemble d'idéologies qui justifient cette hiérarchie de statuts » (205). Il y a quelque chose de juste dans cette critique: dans la mesure où les politiques multiculturelles sont axées sur le principe d'égal respect envers différentes cultures, elles ne peuvent pas répondre à toute les dimensions du racisme. De nombreuses formes de discrimination raciale et d'inégalité raciale systémique comprennent certains aspects symboliques ou socio-économiques de la hiérarchie raciale sans grand rapport avec la différence culturelle. Le multiculturalisme ne doit donc pas être considéré comme le tout de l'antiracisme. Mais reconnaître les limites du multiculturalisme n'est pas pour autant une raison de le rejeter. L'exaltation de la culture européenne au-dessus de toutes les autres et la dévaluation des cultures non blanches sont parties intégrantes du racisme: les politiques multiculturalistes sont par conséquent d'une importance vitale pour lutter contre cet aspect du système de la suprématie blanche.

Bessone soutient que le multiculturalisme implique «un déplacement de la question de la race vers la question de la culture, puis [...] une essentialisation de la culture » (195). Race et culture ne sont pas la même chose, et nous devons prendre garde à l'essentialisme racial: ces deux préoccupations sont donc valables. D'un autre côté, nous ne devrions pas accepter d'être forcés de penser soit à la question de la race, soit à celle de la culture. Les deux sont liés, et nous devons entreprendre la difficile tâche de comprendre leur relation. Bessone nous aide sans doute à voir la difficulté de le faire dans un cadre multiculturaliste. Elle écrit: "même lorsque les théoriciens du multiculturalisme prennent soin de préciser que les groupes culturels ne sont pas des entités homogènes [...] ils passent souvent ensuite sans 
transition à l'étude de la légitimité de revendications émanant de groupes culturels à l'intérieur des sociétés définies par leur diversité culturelle, comme si ces groupes culturels étaient suffisamment cohérents pour s'exprimer d'une seule voix» (20I). C'est un défi pratique parmi d'autres pour éviter l'essentialisme. Elle exprime ici la même inquiétude d'une autre manière: "Promouvant l'élaboration et la visibilité d'une identité collective authentique, [le multiculturalisme] augmente le risque de pression sur les membres individuels de se conformer à la culture du groupe, comme s'il y avait une identité originelle à reconstruire ou réparer» (I99).

Il semble toutefois que ce soit là surtout des raisons d'être encore plus prudent dans notre engagement à valoriser la diversité culturelle et à concevoir des politiques pour manifester cet engagement. Mais ce ne sont pas des raisons de renoncer à cet engagement. Et ce ne sont pas des raisons de séparer d'une part la manifestation et la poursuite de cet engagement dans les sociétés occidentales et, d'autre part, la lutte contre le racisme. Ignorer les dimensions culturelles de la race et du racisme me semble être aussi malavisé que la stratégie «colour-blind» qui ignore la race. Il n'y a aucune raison de penser que nous pouvons remédier au privilège de ce qui est perçu comme culturellement blanc et à la dépréciation sélective de ce qui est associé aux non-blancs (sélective car, en même temps, sont appréciés certains éléments des cultures non blanches, comme la musique et la danse dans le cas des noirs) par le simple moyen indirect qui consiste à s'attaquer à d'autres problèmes. Oui, nous devons éviter d'essentialiser les cultures et de pousser les personnes non blanches à se cantonner dans ce que nous choisissons de définir comme des identités culturelles suffisamment "authentiques». Mais nous devons aussi reconnaître que le désir de nombreuses personnes non blanches d'être sans attache étroite avec leurs cultures soi-disant traditionnelles, ou avec la race qu'on leur a assignée, est souvent, du moins en partie, lié à leur compréhension de la hiérarchie culturelle en place dans la société et à leur désir d'atteindre les avantages du statut dont bénéficient les blancs. Nous devons trouver l'équilibre entre la nécessité de permettre aux individus de construire librement leur identité culturelle en fonction de leurs propres intérêts, et l'élimination des stigmates liés à la déviation par rapport aux normes des blancs.

Prenons le cas controversé des symboles religieux genrés, un problème aujourd'hui particulièrement pressant au Québec. Alia Al-Saji de l'Université McGill a soutenu de façon convaincante que nous ne pouvons pas séparer la question de la perception du voile musulman de celle du processus de racialisation ${ }^{1}$. Voilà pourquoi, dans une perspective antiraciste, nous avons des raisons de nous opposer aux politiques qui instituent des restrictions pour les femmes et les jeunes filles qui portent le voile. Il serait toutefois regrettable qu'une telle opposition soit interprétée comme un soutien aux attitudes et aux

1. Alia Al-Saji, «The Racialization of Muslim Veils: A Philosophical Analysis », Philosophy and Social Criticism 36, 2010, 875-902. 
relations patriarcales. Il devrait être évident que les femmes et les jeunes filles qui ne veulent pas porter le voile soient libres de ne pas le faire et ne se sentent pas obligées de le faire au nom de l'authenticité. Même si elle n'aborde pas la question du voile, c'est ce genre de principes qui semblent conduire Bessone à rejeter le multiculturalisme. Mais ce n'est pas la réponse adéquate. Nous ne devrions pas admettre que l'opposition aux politiques ciblant le voile revienne à soutenir le patriarcat et les restrictions sur les femmes et les jeunes filles. Nous devrions plutôt soutenir les féministes musulmanes qui exigent un respect égal, et pour les femmes et pour les musulmans, tout en rejetant vigoureusement l'idée que les femmes devraient être occidentalisées afin d'être libérées ${ }^{2}$. Il s'agit d'un projet antiraciste, non pas parce que la race et la culture sont une seule et même chose (dans ce cas, non pas parce que l'Islam en tant que religion pourrait être traité comme une race), mais parce que la race et la culture s'entremêlent étroitement dans le développement et l'expression de l'islamophobie occidentale...

Sans distinction de race? est, sans nul doute, une contribution novatrice et bien écrite à la philosophie des races, et je crois que beaucoup des analyses de la race et du racisme qui s'y trouvent sont à la fois exactes et pénétrantes. Je conçois les remarques critiques ci-dessus comme un moyen de stimuler la discussion philosophique sur la race dans une perspective socioconstructiviste. Bessone prend ce qui est sans doute la position classique chez les constructivistes sociaux en mettant de l'avant la façon dont la race implique la division politique des groupes sociaux, à savoir la division des groupes sociaux en fonction du pouvoir et de l'accès aux ressources. En suivant W.E.B. Du Bois, je recommanderai cependant qu'on accorde autant d'attention à l'aspect culturel de la race en tant que forme d'une différence sociale ${ }^{3}$. Ce qui pourrait notamment changer le cours de la discussion, c'est le fait que, tandis que Bessone vise à «la transformation radicale» de la race que nous connaissons avec l'«objectif à long terme» (97) d'éliminer définitivement celle-ci, il est possible, du point de vue que je préconise, de voir l'élimination de la race en tant que division politique comme un premier objectif entraînant une transformation qui permettra aux identités raciales, comprises comme identités culturelles, de demeurer égales à l'avenir.

2. Pour un bon exemple d'une critique féministe musulmane de l'opposition féministe au multiculturalisme, voir Y. Azizah al-Hibri, "Is Western Patriarchal Feminism Good for Third World: Minority Women?» in Susan Moller Okin, Is Multiculturalism Bad for Women? Joshua Cohen, Matthew Howard et Martha C. Nussbaum (ed.), Princeton, NJ, Princeton University Press, I999, 4I-46.

3. Pour en savoir davantage sur le sujet, voir mon article "The Cultural Theory of Race: Yet Another Look at Du Bois's "The Conservation of Races” ", Ethics I 23, 2013, 403426. Pour l'analyse de Bessone sur la race et la culture chez Du Bois, voir Sans distinction de race? p. I24-I 28. 